\title{
CONF-97071/3-1
}

\section{Individual-based Modeling of Fish: Linking to Physical Models and Water Quality ${ }^{1,2}$}

\author{
MECOMVIVI \\ SEP 171997 \\ OSTI
}

\author{
Kenneth A. Rose \\ Environmental Sciences Division \\ P.O. Box 2008 \\ Oak Ridge National Laboratory \\ Oak Ridge, TN 37831-6036
}

Paper Presented at the Army Corp of Engineers Workshop on Aquatic Ecosystem Modeling and Assessment Techniques for Application at CE projects

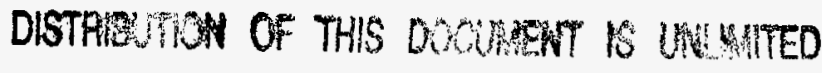
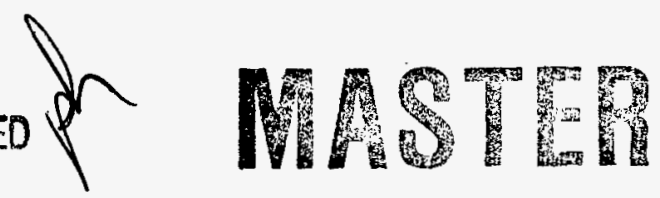

${ }^{1}$ Research sponsored by the Electric Power Research Institute under contract RP2932-2 (DOE No. ERD-87-672) with the U.S. Department of Energy, under contract DE-AC05960R22464 with Lockheed Martin Energy Research Corp.

${ }^{2}$ Publication No. 4692, Environmental Sciences Division, ORNL.

"The submitiod inenuscript tas boen authorized by a

contractor of the U.S. Government under contract

No. DE-ACO5-960R22464. Accondingly, the U.S.

Government retains, a non-exclusive, royalty-froe

lioense to publish of neproduce the publishod form of

this contribution, of allow nhere to do so, for U.S.

Govermment purposes." 


\section{DISCLAIMER}

This report was prepared as an account of work sponsored by an agency of the United States Government. Neither the United States Government nor any agency thereof, nor any of their employees, make any warranty, express or implied, or assumes any legal liability or responsibility for the accuracy, completeness, or usefulness of any information, apparatus, product, or process disclosed, or represents that its use would not infringe privately owned rights. Reference herein to any specific commercial product, process, or service by trade name, trademark, manufacturer, or otherwise does not necessarily constitute or imply its endorsement, recommendation, or favoring by the United States Government or any agency thereof. The views and opinions of authors expressed herein do not necessarily state or reflect those of the United States Government or any agency thereof. 
Introduction

The individual-based modeling approach for the simulating fish population and community dynamics is gaining popularity. Individual-based modeling has been used in many other fields, such as forest succession (Huston 1992) and astronomy (Barnes and Hernquist 1993). The popularity of the individual-based approach is partly a result of the lack of success of the more aggregate modeling approaches traditionally used for simulating fish population and community dynamics. Also, recent recognition that it is often the atypical (non-average) individual that survives has fostered interest in the individual-based approach (Crowder et al. 1992).

Two general types of individual-based models are distribution and configuration (Caswell and John 1992). Distribution models follow the probability distributions of individual characteristics, such as length and age. Configuration models explicitly simulate each individual; the sum over individuals being the population. DeAngelis et al. (1992) showed that, when distribution and configuration models were formulated from the same common pool of information, both approaches generated similar predictions. The distribution approach was more compact (a single equation, with an explicit, analytical solution) and general (changing parameter values was easy), while the configuration approach was more flexible. Simple biological changes, such as making growth rate dependent on previous days' growth rates, were easy to implement in the configuration version but prevented simple analytical solution of the distribution version. 
In this paper, I focus on the configuration approach. I first outline advantages and disadvantages of the configuration and distribution approaches. I then present four examples from research being supported, to varying degrees, by the ongoing Compensatory Mechanisms in Fish Populations (CompMech) Program, sponsored by the Electric Power Research Institute. These examples were selected to highlight the themes of coupling fish to hydrodynamic-water quality models commonly used by the US Army Corps of Engineers (examples 1 and 2) and to demonstrate methods for using individual-based models to examine the effects of dissolved oxygen (DO) (example 3) and zebra mussels (example 4) on fish population and community dynamics. The first two examples illustrate two types of coupling of fish models to physical models. The latter two examples focus on the population-level effects of two commonly encountered water quality problems.

\section{Advantages and Disadvantages}

Table 1 lists advantages and disadvantages of the distribution and configuration approaches to individual-based modeling. The advantages of individual-based modeling over other modeling approaches have been discussed previously (see papers in DeAngelis and Gross 1992; DeAngelis et al. 1994). I focus here on the relative merits of the two approaches to individual-based modeling. The advantages to the distribution approach (compactness, simplicity) arise from its mathematical tractability, whereas the advantages to the 
configuration approach result from the enormous flexibility associated with explicitly simulating individuals. Both the distribution and configuration approaches can encounter solution difficulties; analytical solution of distribution models quickly becomes impossible for even moderate biological complexity, and numerical solution can require advanced mathematics (for the distribution approach) and excessive computer costs (for the configuration approach). Perhaps the most important disadvantage to both distribution and configuration approaches is the lack of individual-level variability associated with reported mean values of parameters and vital rates necessary to truly simulate inter-individual variation.

\section{Examples}

Example 1.--The first example involves a model of walleye pollack eggs and larvae in the Gulf of Alaska (Hinckley et al. 1996). Individual fish are tracked as particles using filtered output from a 3-D hydrodynamics model. Eggs are introduced in a small area (Figure 1). Simple biological rules were imposed on the particles: vertical migration, degree-day development, and temperature-based growth. While the rules imposed were simple, the resulting behavior of the particles in space and time were quite complex.

This example illustrates a direct, hard coupling between the physical and biological models, and also the use of hydrodynamics predictions in a Lagrangian rather than the usual Eulerian perspective. The Lagrangian perspective allows :." the histories of experiences of individual particles to be tracked and recorded . 
what experiences distinguishes survivors from those that perish. The usual Eulerian approach of tracking the mass (number of individuals) at fixed locations would not allow such interpretation. The model is still under development but initial results suggest that survivors tend to be those that get transported along the coast, rather than transported out to sea. Figure 1 shows an example of a model simulation. These results are based on unpublished data (Sarah Hinckley, National Marine Fisheries Service, Seattle, WA., personal communication), but are similar in concept to other simulations shown in Hinckley et al. (1996).

Example 2.-- The second example uses an individual-based young-of-the-year (YOY) model coupled to an age-structured adult model to simulate striped bass population dynamics in the San Fransico Bay (Rose et al. in prep.). The striped bass population has been declining over the past several decades and a variety of causes (including reduced food, increased diversion of water for agricultural use, and reduced adult survival rates) have been blamed for the decline (Stevens et al. 1985).

The adult model tracks the number and mean length of age- 1 and older fish on an annual time step. Age-based maturation determines the number and size distribution of female spawners each year, which is used to initiate the individualbased YOY model. The YOY model computes the number of age-1 survivors from each year's spawners, based on their daily spawning, and the subsequent development, growth, mortality, and movement of their progeny. Four spatial 
boxes are simulated for the YOY life stages. The upper Sacramento River box that leads to the lower Sacramento River box; the lower Sacramento River box joins with the San Joaquin River (Delta) box to form the most downstream Suisin Bay box.

Movement of YOY individuals among the four spatial boxes was based on predictions from a 2-D hydrodynamics model. One hundred simulations of the hydrodynamics model with particles started in historical spawning areas were used to estimate transition probabilities. The transition probabilities are the daily likelihood an individual in one box moves to each of the other boxes or is lost due to water diversions. These transition probabilities were applied to eggs, yolk-sac larvae, and larvae for their first 10 days after spawning. Two flow conditions were simulated: $5000 \mathrm{ft}^{3} / \mathrm{sec}$ Delta outflow which is considered a critically-low condition and $20,000 \mathrm{ft}^{3} / \mathrm{sec}$ which is considered an above-normal condition.

Predicted spatial distributions of individuals mimicked observed distributions. I summarize the spatial distribution by life stage, as the fraction located in the most downstream Bay box (Figure 2). Under higher flow $\left(20,000 \mathrm{ft}^{3} / \mathrm{sec}\right.$ ), a greater proportion of yolk-sac larvae, larvae, and juveniles are found in the Bay. Effects of transport on egg densities are difficult to see because egg densities in the Bay box are low under both low and high flow conditions. Most eggs are found upstream of the Bay box. The striped bass population model is now being used to evaluate the likelihood that reduced food, increased diversions, or reduced adult survival were the cause of the population decline (Rose et al. in review). 
This example, and the walleye pollack example above, both illustrate a direct coupling of biological and physical models; they differ in that the walleye pollack example used hydrodynamic predictions (e.g., velocities) themselves and could have been run simultaneously with the hydrodynamics model, whereas the striped bass example used processed predictions from the hydrodynamics model and was run separately from the hydrodynamics model.

Example 3.-- The third example uses a model that predicts larval fish survival exposed to juvenile fish and sea nettle predators under different DO conditions in a vertically-stratified water column (Breitburg et al. in review). Larval prey are based on naked goby and bay anchovy; predators simulated are sea nettles, and a fish predator sensitive to low DO and tolerant to low DO. The water column is divided into 3 layers (surface, pycnocline, and bottom). The daily growth, survival, and movement of individual fish larvae in a cohort are tracked for 30 days from hatching. Larval growth is fixed at $0.21 \mathrm{~mm} /$ day. Larval survival is determined based on encounters and successful captures by individual predators. Encounter rates and capture success depend on the swim speeds and lengths of the prey and predators. Movement among the surface, pycnocline, and bottom layers is updated daily by randomly assigning individual prey and predators to layers based on specified proportional densities.

DO concentrations affect larval growth rates, predator capture success, and the vertical distributions of prey and predators. All baseline parameter values are 
based on high DO levels. Larval growth rates are specified to decrease with decreasing DO concentrations. Sea nettle capture success increases, while fish predator capture success decreases (more so for the sensitive predator), with decreasing DO concentrations. Proportional densities by layer shift from a distribution proportional to the water volume in each layer under high DO concentrations, to distributions that progressively avoid the bottom layer with decreasing DO concentrations. DO concentrations in the surface layer are always set to no-effects levels. DO concentration in the pycnocline layer depends on the concentrations specified for the bottom layer $13 \mathrm{mg} / \mathrm{L}$ when bottom layer is $0 \mathrm{mg} / \mathrm{L}$ and $4 \mathrm{mg} / \mathrm{L}$ when bottom layer is 0 or $1 \mathrm{mg} / \mathrm{L})$. Parameter values are based on a variety of laboratory, mesocosm, and field experiments and the model is configured to resemble the mesohaline region of the Chesapeake Bay.

Predicted larval survival peaked at intermediate bottom DO concentrations (Figure 3). A variety of simulations involving different shaped water columns and mixes of predators were performed. I show only the results for one of the water column configurations (termed "intermediate" in Breitburg et al. in review).

This example illustrates a soft link between water quality and individualbased fish modeling. One could envision configuring a spatial array of independent water columns and specifying DO concentration by layer based on spatially-explicit predictions from a hydrodynamic-water quality model of the same system. A spatial map of larval survival rates could be generated over time (perhaps seasonally) for different water quality scenarios. 
Example 4.--The fourth example uses an individual-based prey-predator (yellow perch-walleye) model to predict the population-levels effects of zebra mussels (Rutherford et al. in review). The model follows the daily spawning, growth and mortality of individuals of yellow perch and walleye throughout their lifetimes. Adult walleye predation is the major source of mortality on YOY juvenile and yearling yellow perch. The model was developed and corroborated using the extensive 35-year database collected on Oneida Lake.

Zebra mussels are rapidly spreading from their introduction in the Great Lakes area. Zebra mussels are expected to increase water clarity and macrophytes, increase blue green algal blooms, reduce chlorophyll concentrations, and shunt energy from the pelagic to benthic pathways. The increased water clarity and energy shunt effects were imposed in the model, and predicted yellow perch and walleye population dynamics were compared to baseline (no zebra mussel effects) predictions. The increased water clarity effect was imposed by increasing the yellow perch's ability to feed, decreasing the walleye's ability to feed, and increasing the larval mortality rate of both species. Yellow perch can feed under high light conditions, while walleye prefer low light conditions. Larval mortality is assumed to increase with zebra mussels because increased macrophytes will result in increased predation pressure on larval yellow perch ard walleye. The energy shunt effect of zebra mussels was imposed by increasing benthos densities and production rates and decreasing zooplankton densities 
production rates.

Zebra mussels were predicted to lower walleye adult abundances but have little net effect on yellow perch adult abundances (Figure 4). Walleye population abundance decreased from an average of 18 /ha under baseline to 12 /ha under zebra mussels due to the elimination of years of high recruitment. Average annual walleye yield declined $33 \%$ based on numbers (13.5 to $9.1 /$ ha), but due to densitydependent growth of walleye, annual yield based on biomass only slightly declined from baseline values $(9.0$ to $8.4 \mathrm{~kg} / \mathrm{ha})$.

\section{Summary Remarks}

The two general types of individual-based modeling (distribution and configuration) were described and their advantages and disadvantages were discussed. Four examples that use the configuration approach were presented that illustrate direct use of hydrodynamics predictions, use of hydrodynamic predictions to estimate movement probabilities, DO effects on larval survival, and zebra mussel effects on fish population dynamics. Linkages between biological and physical models can vary from highly coupled, in which the models can be run together simultaneously, to soft linkages, in which predicted water quality can be used as input to a biological model. As with any modeling analysis, the questions of interest must be clearly specified first, and then used to properly scale the temporal and spatial and biological resolution of the models. The configuration approach to individual-based modeling offers many advantages for hard and soft coupling to 
physical models and for predicting water quality effects on fish populations.

Acknowledgements.-- I wish to thank Sara Hinckley for sharing her model results on walleye pollack with me. I would also like to thank my co-authors on the other three examples for their collaboration. Research sponsored by the Electric Power Research Institute under contract RP2932-2 (DOE No. ERD-87-672) with the U.S. Department of Energy, under contract DE-AC05-960R22464 with Lockheed Martin Energy Research Corp. This is Publication No. 4692 of the Environmental Sciences Division, ORNL. 


\section{References}

Barnes, J.E., and L.E. Hernquist. 1993. Computer models of colliding galaxies. Physics Today (March): 54-61.

Breitburg, D., K. Rose, and J. Cowan. in review. Linking water quality to fish recruitment: predation mortality of fish larvae in an oxygen-stratified water column. Limnol. Oceanogr.

Caswell, H., and A.M. John. 1992. From the individual to the population in demographic models. pp. 36-61 IN: Individual-based Models and Approaches in Ecology: Population, Communities, and Ecosystems (D.L. DeAngelis and L.J. Gross, eds.), Chapman and Hall, New York.

Crowder, L.B., J.A. Rice, T.J. Miller, and E.A. Marschall. 1992. Empirical and theoretical approaches to size-based interactions and recuitment variability in fishes. pp. 237-255 IN: Individual-based Models and Approaches in Ecology: Population, Communities, and Ecosystems (D.L. DeAngelis and L.J. Gross, eds.), Chapman and Hall, New York.

DeAngelis, D.L., and L.J. Gross. 1992. Individual-based Models and Approaches in Ecology: Population, Communities, and Ecosystems. Chapman and Hall, New York.

DeAngelis, D.L., K.A. Rose, L. Crowder, E. Marschall, and D. Lika. 1993. Fish cohort dynamics: application of complementary modeling approaches. Am. Nat. 142: 604622.

DeAngelis, D.L., K.A. Rose, and M.A. Huston. 1994. Individual-oriented approaches to modeling ecological populations and communities. pp. 390-410 IN: Frontiers in 
Mathematical Biology (S.A. Levin, ed.), Springer-Verlag, New York.

Hinckley, S., A.J. Hermann, and B.A. Megrey. 1996. Development of a spatially explicit, individual-based model of marine fish early life history. Mar. Ecol. Prog. Ser: 139: 47-68.

Huston, M. 1992. Individual-based forest succession models and theory of plant competition. pp. 408-420 IN: Individual-based Models and Approaches in Ecology: Population, Communities, and Ecosystems (D.L. DeAngelis and L.J. Gross, eds.), Chapman and Hall, New York.

Rose, K.A., J.H. Cowan, L.W. Miller, and D.E. Stevens. in prep. Factors affecting the decline in Sacramento-San Joaquin Estuary striped bass: an analysis using coupled individual-based YOY and age-structured adult models.

Rutherford, E.S., K.A. Rose, E.L. Mills, and J.L. Forney. in review. Individual-based model predictions of zebra mussel, Dreissena polymorpha, impacts on walleye (Stizostedion vitreum) an yellow perch (Perca flavescens) populations in Oneida Lake, NY. Can. J. Fish. Aquat. Sci.

Stevens, D.E., D.W. Kohlhorst, L.W. Miller, and D.W. Kelley. 1985. The decline of striped bass in the Sacramento-San Joaquin Estuary, California. Trans. Am. Fish. Soc. 114: 12-30. 
Table 1. Advantages and disadvantages of the distribution and configuration approaches to individual-based modeling.

\begin{tabular}{|c|c|c|}
\hline Advantages: & Distribution & Configuration \\
\hline $\begin{array}{l}\text { compactness of model and solution } \\
\text { equations }\end{array}$ & $x$ & \\
\hline conceptually simple & $\mathrm{x}$ & $\mathrm{x}$ \\
\hline $\begin{array}{l}\text { ease of representing size-based } \\
\text { interactions }\end{array}$ & $\mathrm{x}$ & $\mathrm{x}$ \\
\hline ability to simulate stochasticity & & $x$ \\
\hline ability to mimic plasticity & & $\mathrm{x}$ \\
\hline ability to represent spatial heterogeinty & & $x$ \\
\hline ease of simulating movement & & $\mathrm{x}$ \\
\hline \multicolumn{3}{|l|}{ Disadvantages: } \\
\hline solution difficulties & $x$ & \\
\hline $\begin{array}{l}\text { use of average values in lieu of true } \\
\text { inter-individual variability }\end{array}$ & $\mathrm{x}$ & $x$ \\
\hline problems visualizing multivariate results & & $x$ \\
\hline high computational costs & & $\mathrm{x}$ \\
\hline
\end{tabular}




\section{List of Figures}

Figure 1. Example simulation of the predicted fate (float or particle tracks) of larval walleye pollack in the Gulf of Alaska. Eggs were introduced roughly where the float tracks begin between Kodiak Island and the Alaska Peninsula. These results are based on unpublished data (Sarah Hinckley, National Marine Fisheries Service, Seattle, WA, personal communication), but are similar in concept to other simulations shown in Hinckley et al. (1996).

Figure 2. Predicted fraction of total striped bass by life stage in the most downstream (Bay) box under the critically-low $\left(5000 \mathrm{ft}^{3} / \mathrm{sec}\right)$ and above normal $\left(20,000 \mathrm{ft}^{3} / \mathrm{sec}\right)$ flow conditions. Results are from Rose et al. (in prep.).

Figure 3. Predicted larval survival for the sea nettle, sensitive fish, and tolerant fish predators under $0 \mathrm{mg} / \mathrm{L}, 1 \mathrm{mg} / \mathrm{L}, 2 \mathrm{mg} / \mathrm{L}$, and no-effects ( $\geq 4$ or $\geq 5 \mathrm{mg} / \mathrm{L}$ ) bottom layer DO concentrations. These results correspond to the intermediate water column results reported in Brietburg et al. (in review).

Figure 4. Predicted adult abundances (number/ha) of yellow perch and walleye under baseline and zebra mussel simulations. Results are from Rutherford et al. (in review). 


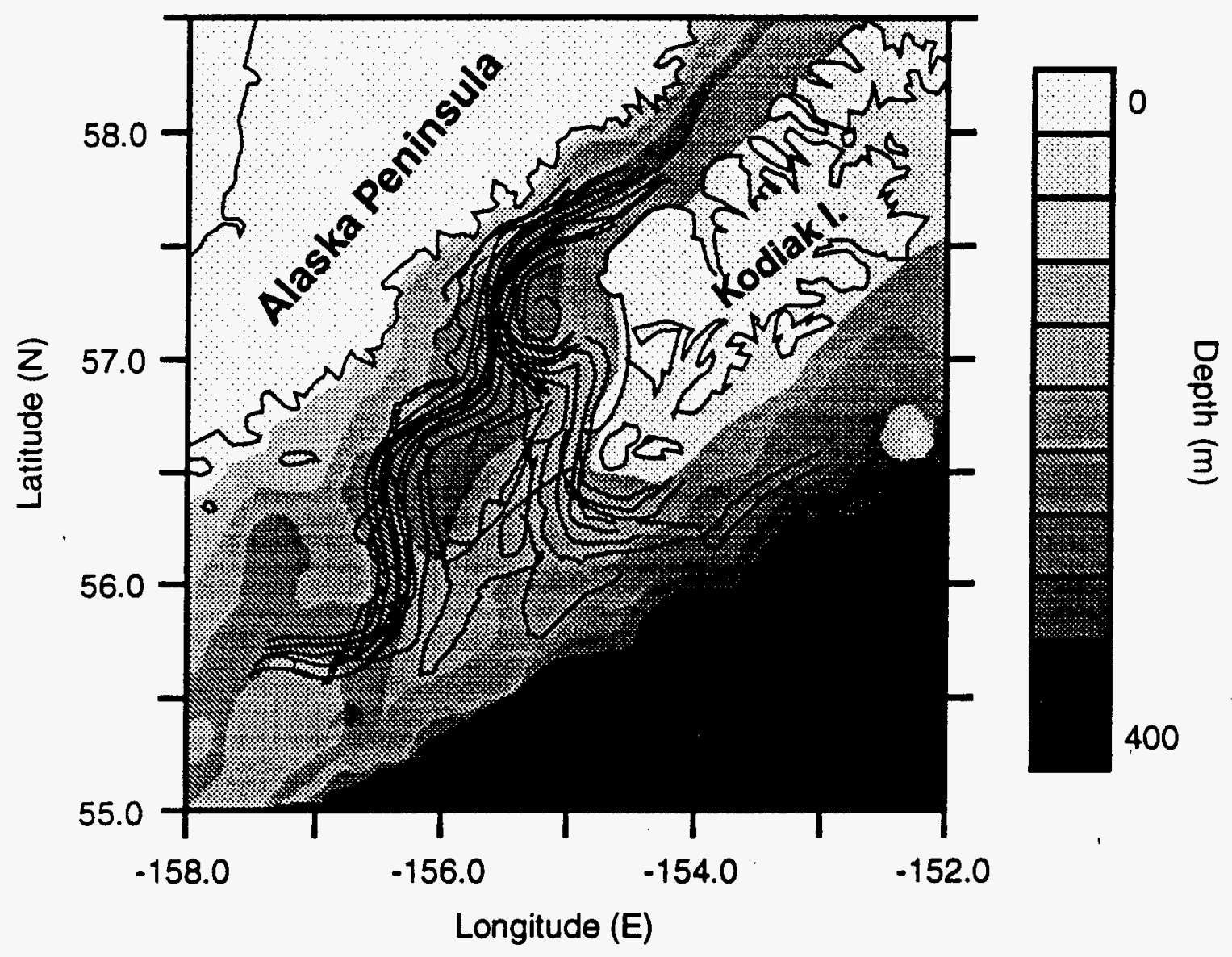

Kg 
ORNL 97-106350/rra

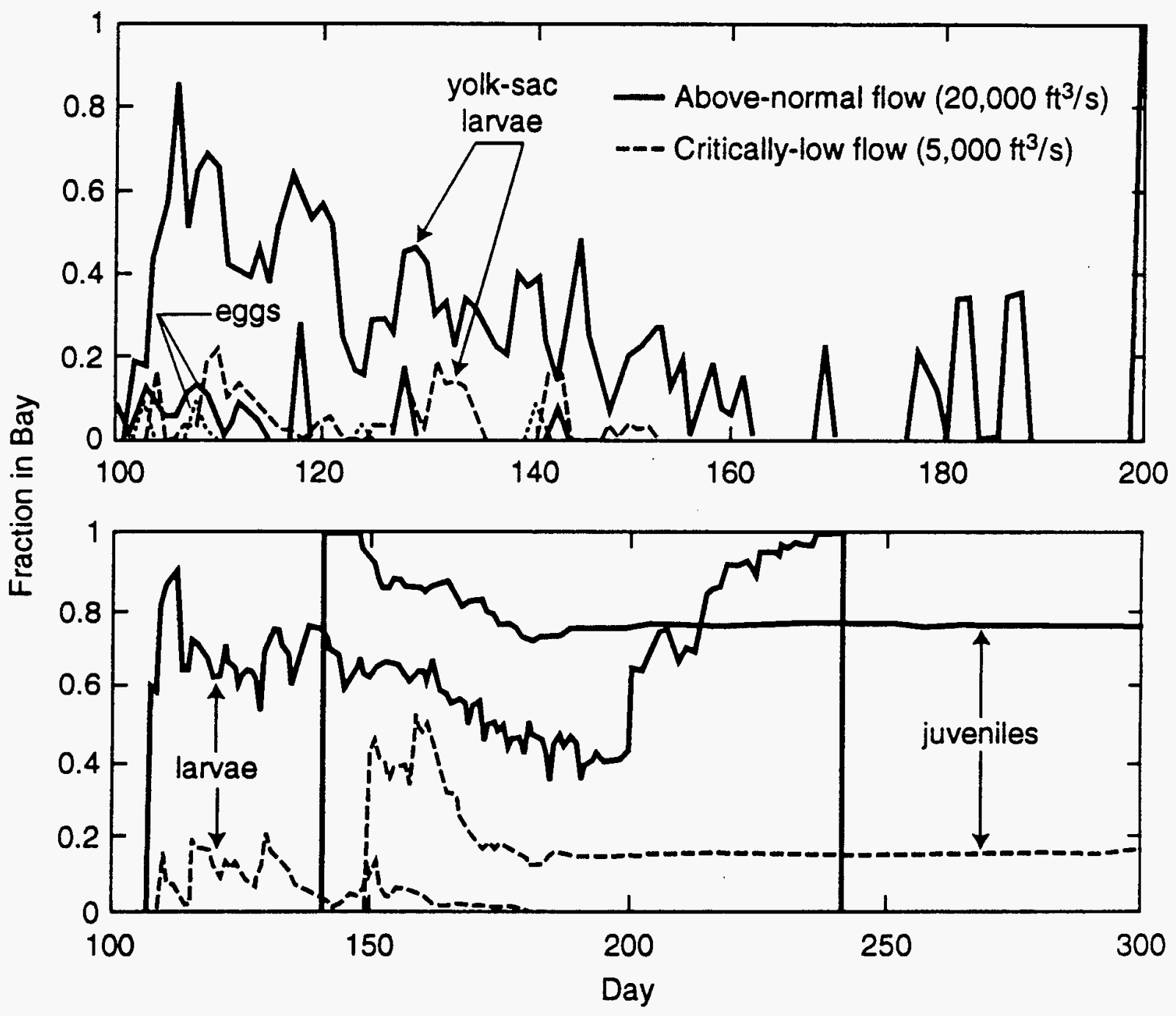

Fy 2 


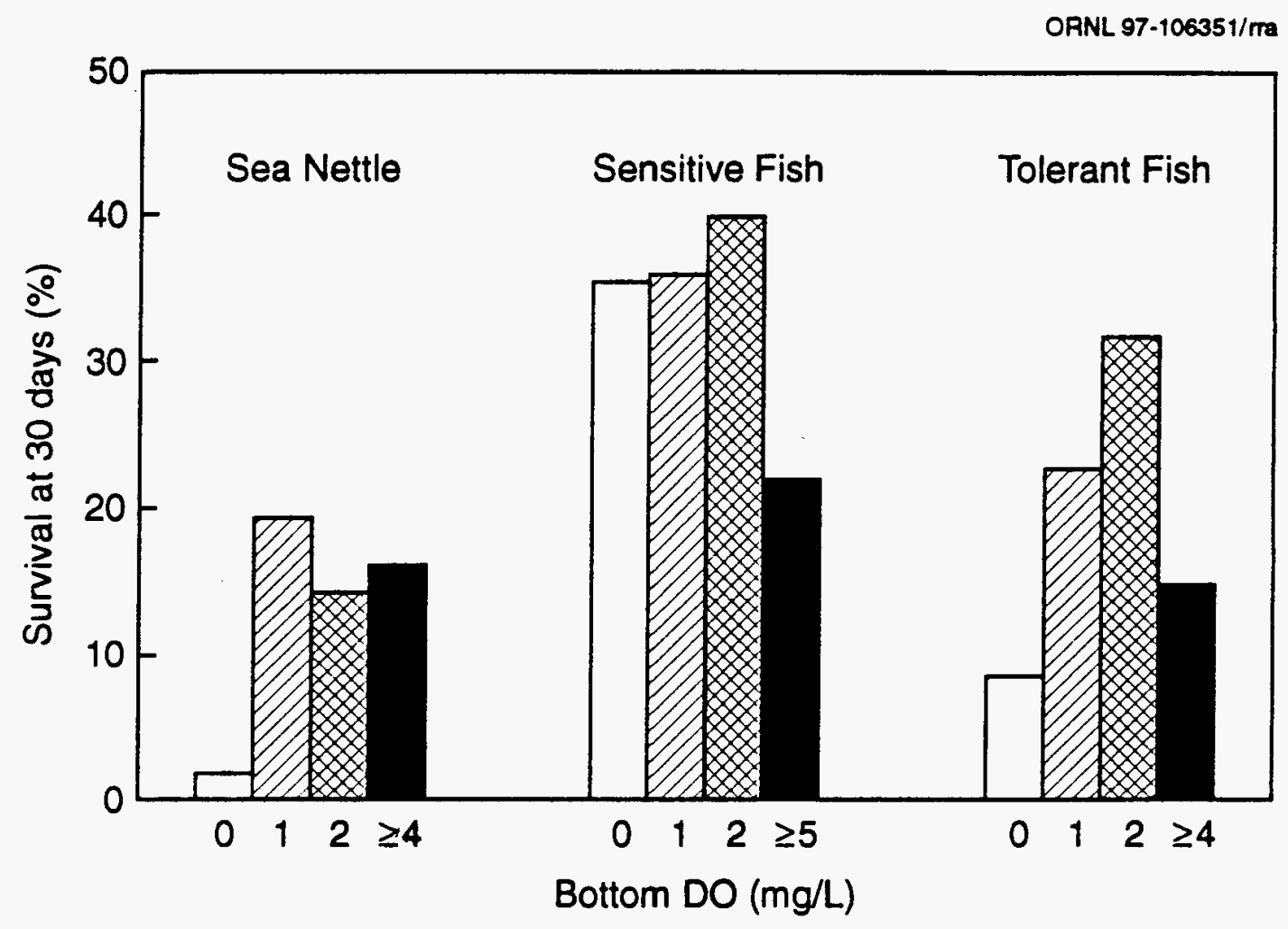

$F_{3} 3$ 
ORNL-DWG 96M-4660R
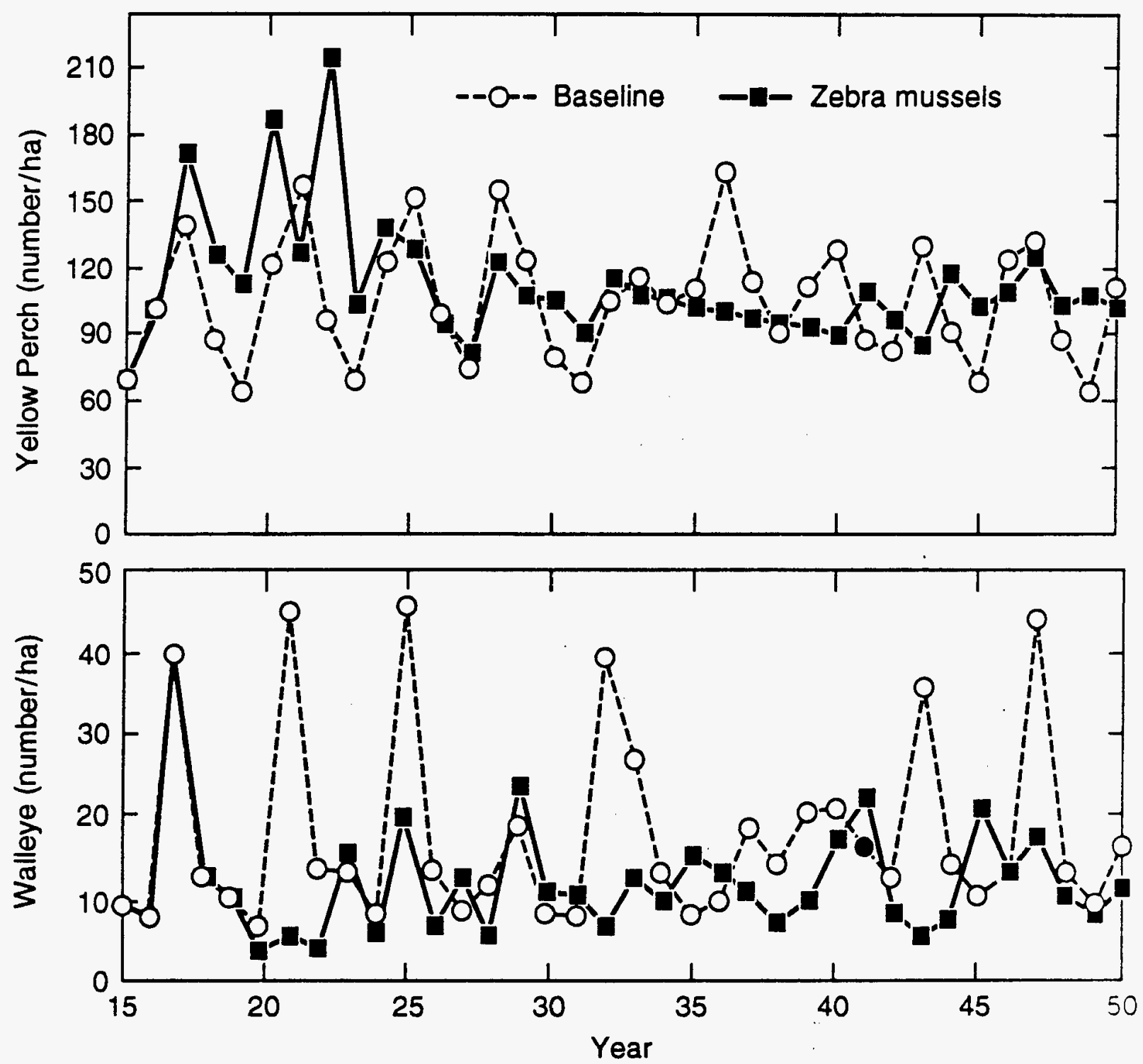


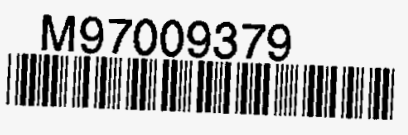

Report Number (14)CONE-9707/13--1

Publ. Date (11) 199708

Sponsor Code (18) EPRF, XF

UC Category (19) UC-OOO, DOE/ER 